\title{
Review dan analisis degister tank dengan fluida POME berdasarkan API 650 menggunakan variable design point method
}

\author{
Hana Hermawan ${ }^{1}$, Winda Wulandari ${ }^{2}$ \\ ${ }^{1}$ Pusat Teknologi Industri Permesinan, Badan Pengkajian dan Penerapan Teknologi \\ Gedung Teknologi 2 Kawasan Puspiptek Serpong, 15314 \\ ${ }^{2}$ Pusat Teknologi Sumber Daya Energi dan Industri Kimia, Badan Pengkajian dan Penerapan Teknologi \\ Gedung Energi 625 Klaster V Kawasan Puspiptek Serpong, 15314 \\ Email korespondensi: hana.hermawan@bppt.go.id
}

\begin{abstract}
Abstrak
POME merupakan produk samping dari produksi minyak kelapa sawit dengan rasio terkandung dalam kelapa sawit 58,3\%. POME dapat dimanfaatkan untuk dijadikan biogas dengan teknologi pengolahan proses anaerobik menggunakan tangki berpengaduk/Continuous Stirred Tank Reactor (CSTR). Tujuan dari kajian ini adalah melakukan review dan analisis digester tank dengan fluida POME berdasarkan standar American Petroleum Institute yaitu API 650: Welded Steel Tanks for Oil Storage menggunakan variable design point method untuk menentukan ketebalan minimum pada setiap shell tergantung pada kedalamannya, sehingga setiap shell dapat memiliki ketebalan yang berbeda sehingga dapat memperkecil volume material dan biaya. Kemudian dilakukan simulasi dengan metode elemen hingga dengan beban dari tekanan hidrostatik yang menghasilkan tegangan maksimum 154,88 MPa, serta deformasi maksimum $5 \mathrm{~mm}$ dan beban dari gaya angin yang menghasilkan tegangan maksimum 1,31 MPa, serta deformasi maksimum 0,5 mm, lalu dibandingkan dengan sifat mekanik material bahwa yield strength terjadi pada tegangan 250-395 MPa sehingga tebal shell hasil perhitungan adalah aman. Kemudian dibandingkan ketebalan minimum hasil perhitungan dengan desain konstruksi yang hasilnya adalah desain konstruksi memiliki tebal yang lebih besar dari perhitungan tebal minimum sehingga desain konstruksi yang akan dipakai adalah aman.
\end{abstract}

Kata kunci: CSTR, API 650, VDPM, metode elemen hingga.

\begin{abstract}
POME is a by-product of palm oil production with a ratio contained in palm oil of 58.3\%. POME can be used as biogas with anaerobic processing technology using a Continuous Stirred Tank Reactor (CSTR). The purpose of this study is to review and analyze the digester tank with POME fluid based on the American Petroleum Institute standard, API 650: Welded Steel Tanks for Oil Storage using a variable design point method to determine the minimum thickness of each shell depending on its depth, so that each shell can have different thickness so as to reduce the volume of material and cost. Then simulations are performed with the finite element method with a load of hydrostatic pressure that produces a maximum stress of $154.88 \mathrm{MPa}$, and a maximum deformation of $5 \mathrm{~mm}$ and a load of wind force that produces a maximum stress of $1.31 \mathrm{MPa}$, and a maximum deformation $0.5 \mathrm{~mm}$, then compared with the mechanical properties of the material that yield strength occurs at a voltage of 250-395 MPa so that the thickness of the calculated shell is safe. Then compare the minimum thickness calculation results with the construction design which results are the construction design has a thickness that is greater than the minimum thickness calculation so that the construction design that will be used is safe.
\end{abstract}

Keywords: CSTR, API 650, VDPM, finite element method.

\section{Pendahuluan}

Indonesia merupakan negara dengan penghasilan kelapa sawit yang terbesar di dunia. Berdasarkan data dari Statistik Perkebunan Indonesia untuk kelapa sawit pada tahun 2015-2017 oleh Direktorat Jenderal Perkebunan, luas areal kelapa sawit (minyak sawit) pada tahun 2015 adalah $4535400 \mathrm{Ha}$ dan total produksi kelapa sawit (minyak sawit) pada tahun 2015 adalah 31070015 [1]. Salah satu produk samping dari produksi minyak kelapa sawit adalah limbah cair kelapa sawit atau palm oil mill effluent yang biasa disingkat dengan POME. Rasio POME yang terkandung di dalam buah kelapa adalah 58,3\% [2].
Dengan rasio POME yang sangat besar tersebut, maka POME dapat dimanfaatkan menjadi energi.

Pengolahan POME menjadi produk yang bermanfaat dan juga dapat mengatasi permasalahan lingkungan harus dengan pemilihan teknologi yang tepat dan handal, serta menganut Teknologi Zero Waste. Umumnya, teknologi pengolahan yang digunakan adalah menggunakan proses anaerobic dengan teknologi covered lagoon dan teknologi tangki berpengaduk secara kontinu atau Continuous Stirred Tank Reactor (CSTR) [3]. Dalam kajian ini, teknologi yang dipilih adalah teknologi tangki berpengaduk secara kontinu atau Continuous Stirred Tank Reactor 
(CSTR). Pengolahan POME menggunakan CSTR merupakan sebuah tantangan karena POME merupakan effluent yang mengandung material kompleks seperti mengandung konsentrasi tinggi, konsentrasi bahan organik, minyak dan gemuk dan padatan tersuspensi [4]

Penelitian tentang CSTR telah dilakukan dengan hasil menyatakan bahwa CSTR merupakan jenis reaktor yang cocok untuk pemrosesan substrat POME yang memiliki Suspended Solid (SS) dan free fat, oil and greas (FOG) yang tinggi [5]. CSTR mudah dioperasikan dan dapat diproses dengan baik jika kontak dengan air limbah dan mikroorganisme. Oleh karena itu, dibutuhkan review dan analisis desain untuk CSTR untuk mengkonversi POME menjadi biogas [6]. Tujuan dari kajian ini adalah melakukan review dan analisis digester tank dengan fluida POME berdasarkan standar American Petroleum Institute yaitu API 650: Welded Steel Tanks for Oil Storage menggunakan variable design point method untuk menentukan ketebalan minimum pada setiap shell, sehingga setiap shell dapat memiliki ketebalan yang berbeda sehingga dapat memperkecil volume material dan biaya [7].

\section{Metode}

Perhitungan untuk mendapatkan ketebalan minimum storage tank menggunakan Variable Design Point Method pada standar API 650. Metode tersebut menggunakan titik yang berbeda-beda berdasarkan kedalaman tangki untuk menentukan ketebalan shell yang berbeda sehingga dapat memperkecil penggunaan shell plate yang sama karena berdasarkan pada kebutuhan tebal karena beban yang dialaminya sehingga dapat memperkecil biaya untuk pembangunan shell tank tersebut. Tabel 1 menunjukkan kebutuhan desain dari storage tank.

Tabel 1. Kebutuhan desain tangki.

\begin{tabular}{cc}
\hline \multicolumn{2}{c}{ Storage Tank Details } \\
\hline Tank capacity & $2000 \mathrm{~m}^{3}$ \\
Tank diameter $(D)$ & $14 \mathrm{~m}$ \\
Tank height $(H)$ & $13.5 \mathrm{~m}$ \\
Height of each shell $\left(h_{1}\right)$ & $1.5 \mathrm{~m}$ \\
Specific gravity of product $(G)$ & 1 \\
Minimum thickness required as & 8 \\
per safety norms & 3 \\
Corrosion allowance $(C A)$ & Mild steel \\
Tank material & $220 \mathrm{MPa}$ \\
Design stress $\left(S_{D}\right)$ & $236 \mathrm{MPa}$ \\
Hydrostatic stress $\left(S_{t}\right)$ &
\end{tabular}

\section{Hasil dan Pembahasan}

Berdasarkan kebutuhan desain tangki yang disebutkan pada Tabel 1, maka dilakukan perhitungan dengan perhitungan sebagai berikut.

\section{Perhitungan Shell Plates}

Perhitungan shell plates digunakan untuk mendapatkan bottom shell course pada dua kondisi, design condition menggunakan Persamaan (1), sehingga didapatkan besar bottom shell course sebesar 7,12 mm, sedangkan hydrostatic condition menggunakan Persamaan (2) dan didapatkan besar bottom shell course sebesar 4,12 mm [8].

$$
\begin{aligned}
& \mathrm{t}_{1 \mathrm{~d}}=\left[1.06-\frac{0.0696 D}{H} \sqrt{\frac{H G}{S d}}\right]\left[\frac{4.9 H D G}{S d}\right]+C A \\
& \mathrm{t}_{1 \mathrm{t}}=\left[1.06-\frac{0.0696 D}{H} \sqrt{\frac{H}{S t}}\right]\left[\frac{4.9 H D}{S t}\right]
\end{aligned}
$$

Dapat disimpulkan bahwa $\mathrm{t}_{1 \mathrm{~d}}>\mathrm{t}_{1 \mathrm{t}}$, sehingga dipilih $\mathrm{t}_{1 \mathrm{~d}}$ sebagai ketebalan minimum dari bottom shell sebesar 7,12 mm, kemudian dipilih $\mathrm{t}_{1}$ sebesar $9 \mathrm{~mm}$. Persamaan (3) dan Persamaan (4) digunakan untuk memeriksa rasio.

$\frac{L}{H} \leq \frac{1000}{6}$

$\mathrm{L}=(500 \mathrm{Dt})^{0.5}$

Kemudian didapatkan rasio $17.53 \leq 166.67$, sehingga memenuhi persyaratan untuk menggunakan Variable Design Point Method (VDPM).

\section{Penentuan $2^{\text {nd }}$ Shell Course}

Untuk menentukan ketebalan $2^{\text {nd }}$ shell course baik secara kondisi desain dan kondisi hydrostatic, maka perlu ditentukan rumus perhitungan tebal $2^{\text {nd }}$ shell course dengan Persamaan (5), sehingga didapatkan $6,34[9]$

$\frac{h 1}{(r t 1)^{0.5}}$

Penggunaan rumus perhitungan tebal $2^{\text {nd }}$ shell course perlu digunakan aturan yakni: (a) Jika hasil rasio lebih kecil atau sama dengan 1,375, maka $t_{2}=t_{1}$, (b) Jika hasil rasio lebih besar atau sama dengan 2,625, maka $\mathrm{t}_{2}=\mathrm{t}_{2 \mathrm{a}}$, dan (c) Jika hasil rasio lebih besar dari 1,375, tetapi kurang dari 2,625, maka digunakan Persamaan (6) berikut ini.

$t 2=t 2 a+(t 1-t 2 a)\left[2.1-\frac{h 1}{1.25(r t)^{0.5}}\right]$

Berdasarkan hasil perhitungan yang didapatkan dan aturan yang digunakan adalah rasio lebih besar atau sama dengan 2,625, maka $\mathrm{t}_{2}=\mathrm{t}_{2 \mathrm{a}}$.

\section{Perhitungan ta}

Perhitungan dilakukan dengan menentukan $h$ terlebih dahulu pada Persamaan (7), kemudian perhitungan dengan design condition seperti pada Persamaan (8) 
dan menentukan design point seperti pada Persamaan (9) hingga Persamaan (14).

$\mathrm{h}=9-\mathrm{h} 1=12$ meter

$t 2 a=\frac{4.9 D\left(H-\frac{x}{1000}\right) G}{S d}+C A$

$x 1=0.61 \sqrt{r t u}+320 C H$

$x 2=1000 \mathrm{CH}$

$x 3=1.22 \sqrt{r t u}$

$t u=\frac{4.9 D(H-0.3) G}{S d}$

$K=\frac{t l}{t u}$

$C=\frac{\sqrt{K}(K-1)}{1+K^{1.5}}$

Kemudian dibuat dalam beberapa design point berbeda berdasarkan $t_{u}$ yang didapatkan seperti ditunjukkan pada Tabel 2, dapat disimpulkan bahwa $\mathrm{t}_{2 \mathrm{a}}=\mathrm{t}_{2}$, sebesar $6,74 \mathrm{~mm}$.

Tabel 2. Perhitungan $t_{2 a}$ shell kedua.

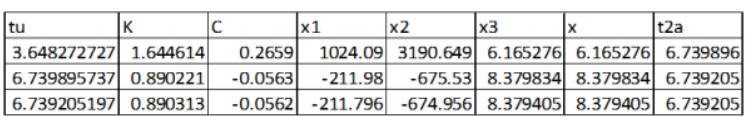
\begin{tabular}{|r|r|r|r|r|r|r|r|r|}
\hline 6.739895737 & 0.890221 & -0.0563 & -211.98 & -675.53 & 8.379834 & 8.379834 & 6.739205 \\
\hline 6.739205197 & 0.890313 & -0.0562 & -211.796 & -674.956 & 8.379405 & 8.379405 & 6.739205 \\
\hline
\end{tabular}

Hydrostatic condition didapatkan dengan menggunakan Persamaan (15) hingga Persamaan (17) berikut.

$t u=\frac{4.9 D(H-0.3) G}{S d}$

$K=\frac{t l}{t u}$

$C=\frac{\sqrt{K}(K-1)}{1+K^{1.5}}$

Kemudian dibuat dalam beberapa design point berbeda berdasarkan $t_{u}$ yang didapatkan seperti ditunjukkan pada Tabel 3, dapat disimpulkan bahwa $\mathrm{t}_{2 \mathrm{a}}=\mathrm{t}_{2}$, sebesar $3,49 \mathrm{~mm}$.

Tabel 3. Perhitungan $\mathrm{t}_{2 \mathrm{t}}$ shell kedua.

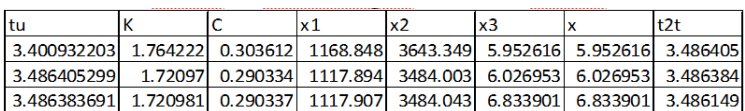
\begin{tabular}{|r|r|r|r|r|r|r|r|r|}
\hline 3.486405299 & 1.72097 & 0.290334 & 1117.894 & 3484.003 & 6.026953 & 6.026953 & 3.486384 \\
\hline 3.486383691 & 1.720981 & 0.290337 & 1117.907 & 3484.043 & 6.833901 & 6.833901 & 3.486149 \\
\hline
\end{tabular}

Berdasarkan perbandingan ketebalan pada perhitungan design condition dan hydrostatic condition, didapatkan $\mathrm{t}_{2 \mathrm{a}}>\mathrm{t}_{2 \mathrm{t}}$, maka dipilih $6,4 \mathrm{~mm} \approx$ $7 \mathrm{~mm}$. Untuk perhitungan tebal shell course plate ketiga hingga kesembilan menggunakan metode yang sama dan didapatkan ketebalan untuk semua shell course seperti ditunjukkan pada Tabel 4 berikut.
Tabel 4. Ketebalan setiap shell.

\begin{tabular}{cc}
\hline Shell Courses & $\begin{array}{c}\text { Ketebalan } \\
(\mathbf{m m})\end{array}$ \\
\hline Pertama & 9 \\
Kedua & 7 \\
Ketiga & 7 \\
Keempat & 6 \\
Kelima & 6 \\
Keenam & 5 \\
Ketujuh & 5 \\
Kedelapan & 4 \\
Kesembilan & 4 \\
\hline
\end{tabular}

\section{Design Bottom Plate}

Menurut API 650, ketebalan minimum dari bottom plate adalah $6 \mathrm{~mm}$, ditambah dengan corrosion allowance $3 \mathrm{~mm}$ seharusnya menjadi $9 \mathrm{~mm}$, namun dipilih $10 \mathrm{~mm}$ dengan pertimbangan ketersediaan di pasaran.

\section{Design Annular Plate}

Perhitungan didapatkan dengan menggunakan Persamaan (18) dan Persamaan (19), sehingga didapatkan Product stress sebesar 154,88 MPa dan Hydrostatic stress sebesar 96,76 MPa.

Product stress $=\frac{t d \times S d}{\text { terpilih }- \text { corrosion allowance }}$

Hydrostatic stress $=\frac{t t \times S t}{t \text { terpilih }}$

Berdasarkan rekomendasi API 650 pada Tabel 5, dengan mengacu pada tegangan produk yang terjadi pada bottom shell course, tebal annular plate adalah $6 \mathrm{~mm}$ ditambahkan dengan corrosion allowance 3 $\mathrm{mm}$, sehingga didapatkan tebal $9 \mathrm{~mm}$.

Tabel 5. Rekomendasi tebal bottom plate API 650.

\begin{tabular}{lcccc}
\hline Plate Thickness of First $_{\text {Shell Course }(\mathrm{mm})}$ & \multicolumn{4}{c}{ Stress $^{\mathrm{b}}$ in First Shell Course (MPa) } \\
\cline { 2 - 5 } & $\leq 190$ & $\leq 210$ & $\leq 220$ & $\leq 250$ \\
\hline$t \leq 19$ & 6 & 6 & 7 & 9 \\
$19<t \leq 25$ & 6 & 7 & 10 & 11 \\
$25<t \leq 32$ & 6 & 9 & 12 & 14 \\
$32<t \leq 40$ & 8 & 11 & 14 & 17 \\
$40<t \leq 45$ & 9 & 13 & 16 & 19 \\
\hline
\end{tabular}

\section{Analisa Beban}

Analisa beban dihitung dengan menggunakan perhitungan tekanan hidrostatik yang ditunjukkan pada Persamaan (20), kemudian tekanan hidrostatik tiap kedalaman shell ditunjukkan pada Tabel 6 berikut.

$p=\rho g H$ 
Tabel 6. Tekanan hidrostatik berdasarkan kedalaman shell.

\begin{tabular}{cc}
\hline Shell Courses & $\begin{array}{c}\text { Tekanan } \\
(\boldsymbol{P a})\end{array}$ \\
\hline Pertama & 127137,6 \\
Kedua & 113011,2 \\
Ketiga & 98884,8 \\
Keempat & 84758,4 \\
Kelima & 70632 \\
Keenam & 56505,6 \\
Ketujuh & 42379,2 \\
Kedelapan & 28252,8 \\
Kesembilan & 14126,4 \\
\hline
\end{tabular}

\section{Analisa Beban Udara}

Analisa beban udara dihitung dengan menggunakan perhitungan gaya hambat (drag force) yang ditunjukkan pada Persamaan (21), sehingga didapatkan besar gaya hambat yakni 32952,62 N.

\section{Hasil Simulasi dan Observasi}

Statik analisis dilakukan dengan tekanan hidrostatik, data yang digunakan ditunjukkan pada Tabel 7 berikut.

Tabel 7. Massa jenis POME.

\begin{tabular}{l|c}
\hline \multicolumn{1}{c|}{ Specifications } & Value \\
\hline POME density $\left(\times 10^{3} \mathrm{~kg} \mathrm{~m}^{-3}\right)$ & 0.98 \\
\hline Produced biogas per $1 \mathrm{t}-\mathrm{POME}\left(\mathrm{m}^{3} \mathrm{t}^{-1}\right)$ & 23 \\
\hline POME temperature $\left({ }^{\circ} \mathrm{C}\right)$ & 80 \\
\hline
\end{tabular}

Simulasi yang dilakukan kemudian menghasilkan hasil seperti ditunjukkan pada Gambar

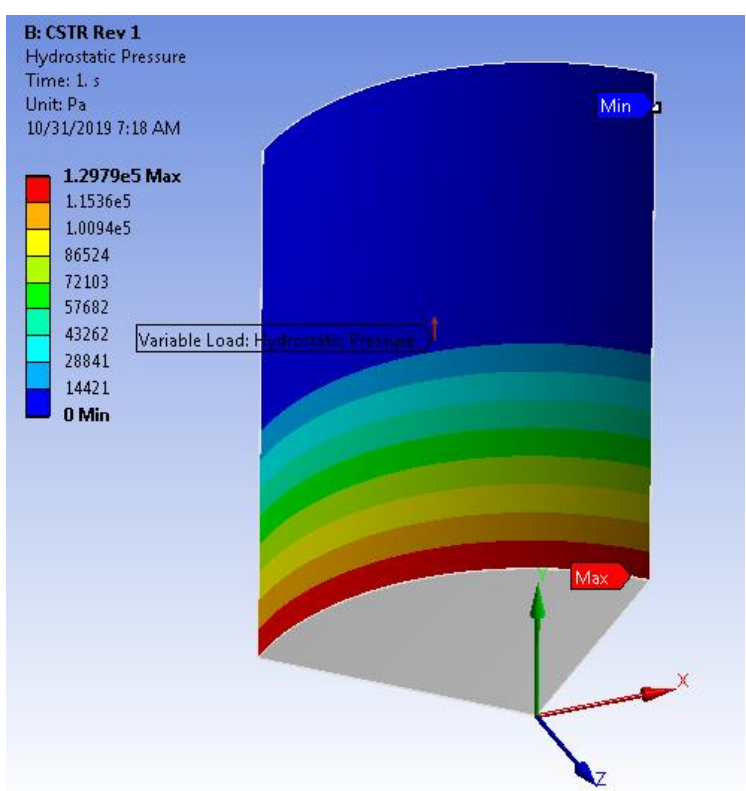

Gambar 1. Tekanan hidrostatik.

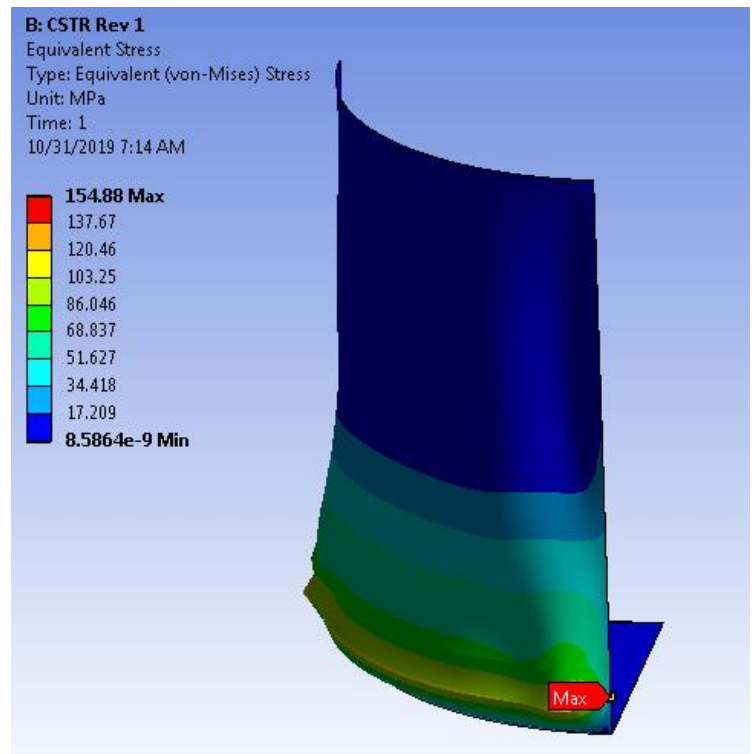

Gambar 2. Equivalent stress.

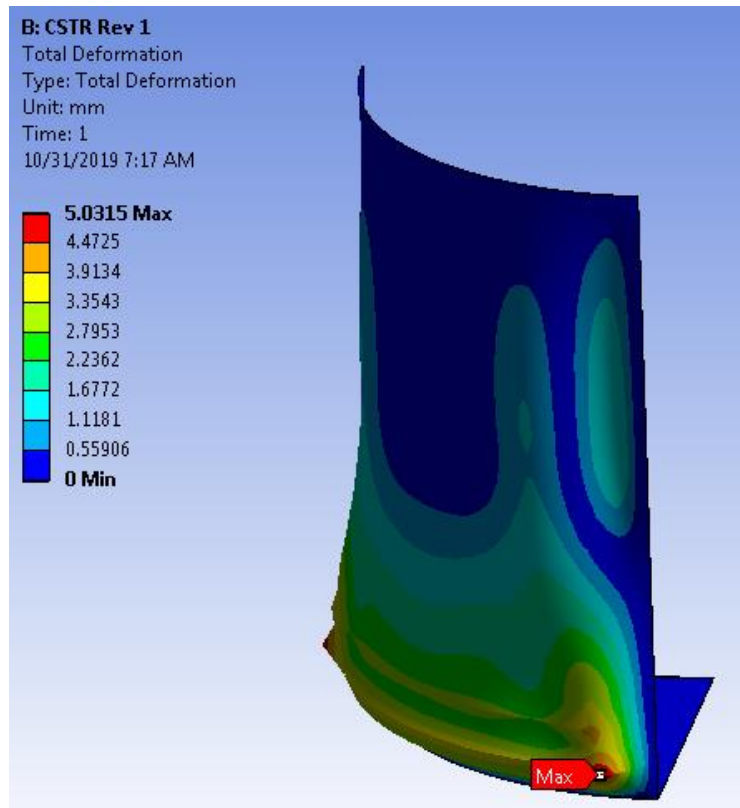

Gambar 3. Total deformation. 


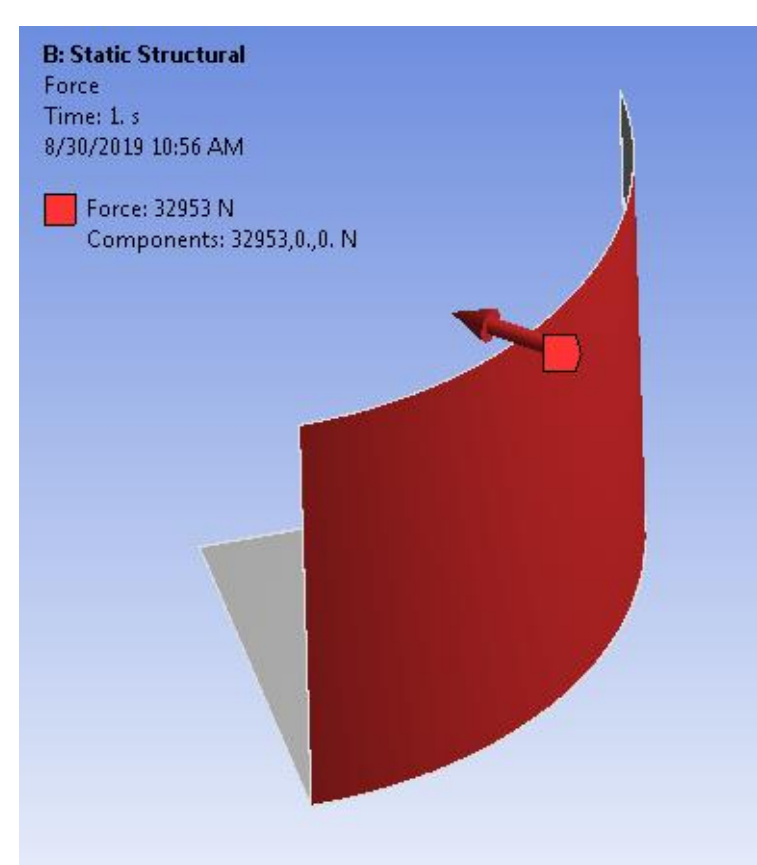

(a)

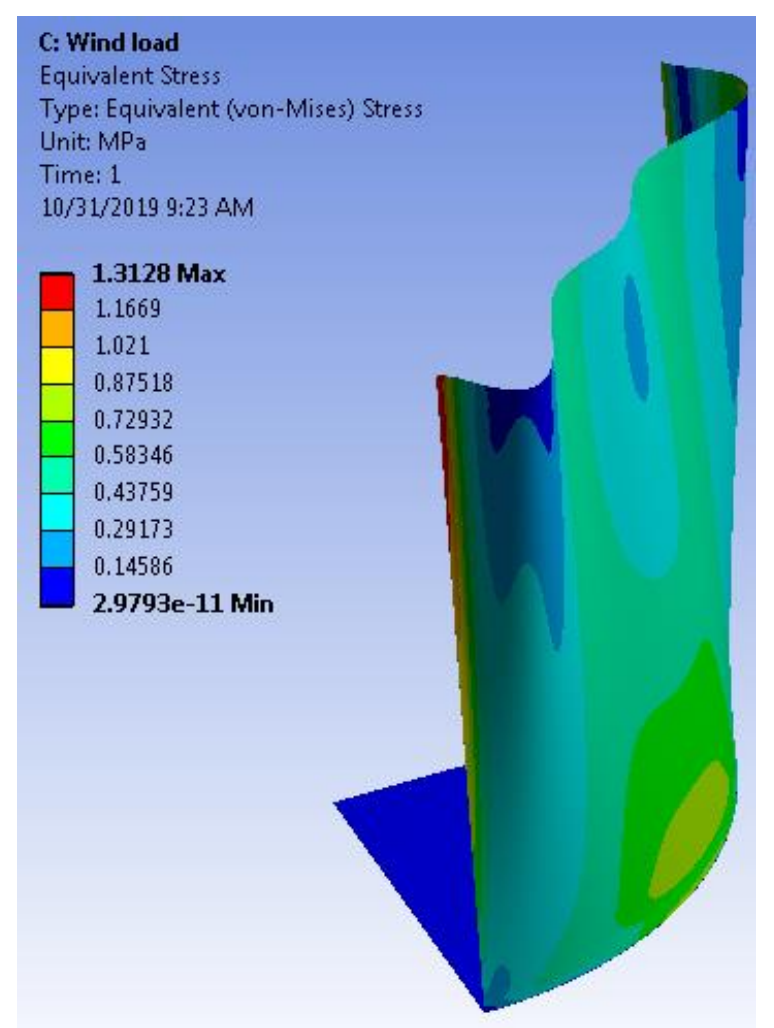

(b)

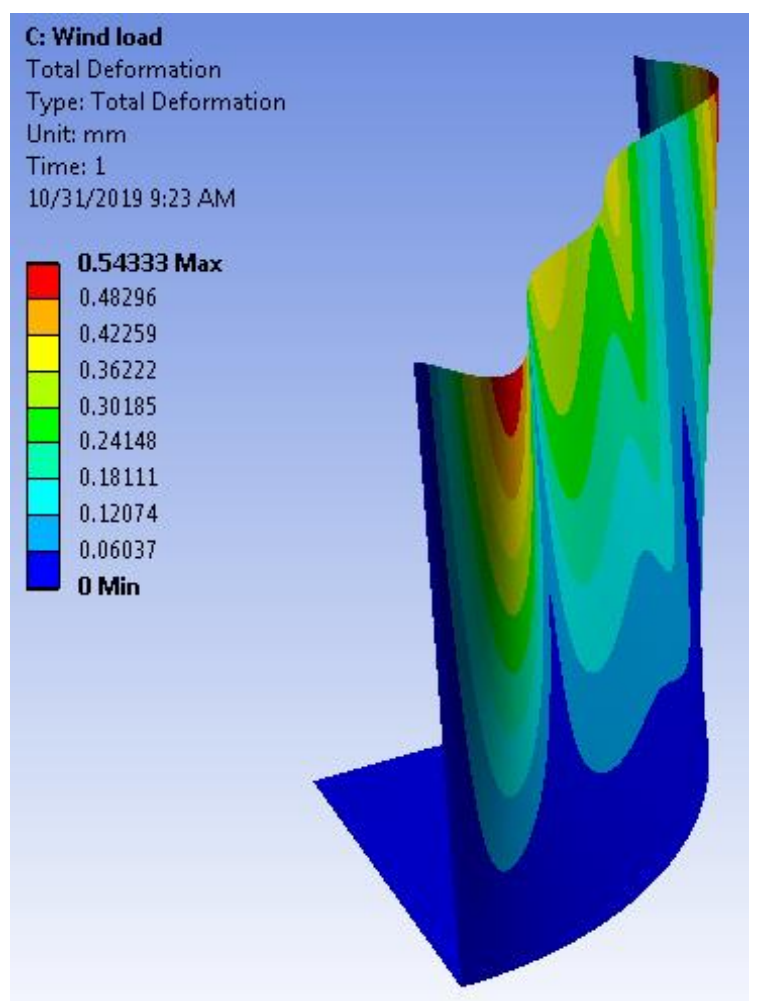

(c)

Gambar 4. Simulasi (a) Force (gaya angina), (b) Equivalent stress dan (c) Total deformation.

Berdasarkan analisis dari hasil simulasi FEM tersebut, didapatkan bahwa tegangan maksimum adalah 154,88 MPa dan terdapat pada shell pertama paling bawah dan sifat mekanik Mild steel ditunjukkan pada Tabel 8. Total deformasi yang terjadi adalah sebesar $5 \mathrm{~mm}$ dan berada di bagian shell pertama paling bawah. Tegangan maksimum yang dialami oleh tangki akibat gaya angina adalah 1,31 $\mathrm{MPa}$ dengan deformasi maksimum adallah $0,5 \mathrm{~mm}$.

Tabel 8. Sifat mekanik mild steel.

\begin{tabular}{|l|l|}
\hline Modulus of Elasticity & $200-250 \mathrm{GPa}$ \\
\hline Yield Strength & $250-395 \mathrm{MPa}$ \\
\hline Tensile Strength & $345-580 \mathrm{MPa}$ \\
\hline Elongation & $26 \%-47 \%$ \\
\hline Hardness & $107.5-172.5 \mathrm{HV}$ \\
\hline
\end{tabular}

Perbandingan dengan ketebalan shell pada General Arrangement (GA) dan desain API 650 ditunjukkan pada Tabel 9 berikut. 
Tabel 9. Ketebalan shell (a) hasil perhitungan dan (b) desain API 650.

(a)

(b)

\begin{tabular}{|l|c||l|c|}
\hline Shell courses & $\begin{array}{c}\text { Ketebalan } \\
(\mathrm{mm})\end{array}$ & Shell courses & $\begin{array}{c}\text { Ketebalan } \\
(\mathrm{mm})\end{array}$ \\
\hline Pertama & 9 & Pertama & 10 \\
\hline Kedua & 7 & Kedua & 10 \\
\hline Ketiga & 7 & Ketiga & 8 \\
\hline Keempat & 6 & Keempat & 8 \\
\hline Kelima & 6 & Kelima & 8 \\
\hline Keenam & 5 & Keenam & 8 \\
\hline Ketujuh & 5 & Ketujuh & 8 \\
\hline Kedelapan & 4 & Kedelapan & 8 \\
\hline Kesembilan & 4 & Kesembilan & 8 \\
\hline \multicolumn{3}{|l}{}
\end{tabular}

\section{Kesimpulan}

Berdasarkan hasil dari simulasi menggunakan metode elemen hingga dengan pembebanan hidrostatik, didapatkan tegangan maksimum yang terjadi sebesar $154,88 \mathrm{MPa}$ dengan deformasi total $5 \mathrm{~mm}$ dan tegangan terbesar akibat beban angin adalah 1,31 Mpa dengan deformasi total $0,5 \mathrm{~mm}$. Jika dibandingkan dengan yield strength dari material strength Mild steel adalah 250-395 MPa maka dapat dikatakan tegangan yang terjadi masih aman. Sehingga ketebalan shell dari Drawing General Arrangement dapat digunakan dan aman. Untuk kedepannya sebaiknya dilakukan pula simulasi beban akibat pergerakkan fluida (sloshing) untuk mengetahui pengaruhnya terhadap shell.

\section{Daftar Pustaka}

[1] Pertanian, D.J.P.K., 2016, Statistik Perkebunan Indonesia Tahun 2015 - 2017, p. 14.

[2] Hambali, E. and M. Rivai, The Potential of Palm Oil Waste Biomass in Indonesia in 2020 and 2030, 2017, IOP Conference Series: Earth and Environmental Science, 65: p. 012050.

[3] Garritano, A.N., et al., 2018, Palm oil mill effluent (POME) as raw material for biohydrogen and methane production via dark fermentation. Renewable and Sustainable Energy Reviews, 92: p. 676-684.

[4] Khadaroo, S.N.B.A., et al., 2019, Applicability of various pretreatment techniques to enhance the anaerobic digestion of Palm oil Mill effluent (POME): A review. Journal of Environmental Chemical Engineering, 7(5): p. 103310.

[5] Visal B., Sibin B., 2017, Design and Analysis of Storage Tank. International Journal of Innovative Research in Science, Engineering and Technology.

[6] "American Petroleum Institute (API) 650: Welded Steel Tanks for Oil Storage", 11th Edition.

[7] Teager, A., Methodology and Instrumentation: Tensile Testing Lab, University of Liverpool.
[8] Indonesia, M.E.d.S.D.M.R., 2014, Pembelian Tenaga Listrik dari Pembangkitan Listrik Tenaga Biomassa dari Pembangkit Listrik Tenaga Biomassa dan Pembangkit Listrik Tenaga Biogas oleh PT Perusahan Listrik Negara (Persero). Nomor 27 Tahun 2014.

[9] Matseh, I., 2018, Processing of palm oil mill wastes based on zero waste technology. IOP Conference Series: Materials Science and Engineering, 309: p. 012136. 